Pacific Journal of Mathematics

DIVISIBILITY PROPERTIES OF CERTAIN FACTORIALS 


\section{DIVISIBILITY PROPERTIES OF CERTAIN FACTORIALS}

\section{J. Chidambaraswamy}

It is well known that multinomial coefficients are integers; i.e., if the integers $a_{i}$ are nonnegative and $a=\sum_{i=1}^{m} a_{i}$, then $\amalg_{i=1}^{m}\left(a_{i}\right) ! \mid a !$. This property may hold good in special cases even though $\sum_{i=1}^{m} a_{i}>a$. In fact, for each integer $x \geqq 0$, $x !(x+1) ! \mid(2 x) !$, and it has been asked by Erdos, as a research problem in the 1947 May issue of the Monthly, whether, for a given $c \geqq 1$, there exists an infinity of integers $x$ such that $x !(x+c) ! \mid(2 x) !$. This problem has been gradually generalized and improved upon by Mordell, Wright, McAndrew, the author, and N. V. Rao. In particular, Rao considers the quotient $Q(x)=((g(x)+h(x)) !) /((g(x)+k) !(h(x)) !)$, where $k$ is a positive integer, and $g(x)$ and $h(x)$ are integer coefficient polynomials of positive degree with positive leading coefficients and proves that some multiple of $Q(x)$ is integral infinitely of ten: a result which includes all the earlier results. In this paper, among other things, this result of Rao has been generalised and improved upon by taking the polynomials over the rationals and by reducing the multiplying factor of $Q(x)$ as obtained by Rao.

Throughout the following $i, j, k, r$, and $n$ denote positive integral variables and all small letters, unless explicitly mentioned otherwise denote positive integers. As usual, $(a, b)$ and $\{a, b\}$ denote respectively the G.C.D. and L.C.M. of $a$ and $b$. For any polynomials $X(x)$ and $Y(x)$ (not both zero) over the rationals, $(X(x), Y(x))$ denote their monic G. C. D. over the rationals. $m$ being $\geqq 1, t_{1}, t_{2}, \cdots, t_{m}$ are integers each greater than 1 . For $1 \leqq i \leqq m$ and $1 \leqq j \leqq t_{i}, f_{i j}(x)$ is a polynomial of positive degree over the rationals with positive leading coefficient; $a_{i j}$ and $c_{i j}$ are nonnegative integers, $r_{i j}$ is a positive rational and $k_{i j}$ is a positive integer. Also, $r_{i}$ is a nonnegative integer for each $i$ in $1 \leqq i \leqq m$. We use the following symbolism.

$$
\begin{aligned}
f_{i}(x) & =\sum_{k=1}^{t_{i}} f_{i k}(x) ; & F_{i j}(x) & =\sum_{\substack{k=1 \\
k \neq j}}^{t_{i}} f_{i k}(x) \\
A_{i} & =\sum_{k=1}^{t_{i}} a_{i k} ; & A_{i j} & =\sum_{\substack{k=1 \\
k \neq j}}^{t_{i}} a_{i k} \\
R_{i} & =\sum_{k=1}^{t_{i}} r_{i k} ; & R_{i j} & =\sum_{\substack{k=1 \\
t_{i} \\
k \neq j}} r_{i k} ;
\end{aligned}
$$

Received January 6, 1965. This paper and the following one are taken from the author's Ph. D. thesis submitted in May 1964, under the title of this paper, to the Graduate Division, University of California, Berkeley. 


$$
\begin{array}{cc}
K_{i}=\sum_{r=1}^{t_{t}} k_{i r} ; & K_{i j}=\sum_{\substack{r=1 \\
r \neq j}}^{t_{i}} k_{i r} \\
C_{i}=\sum_{r=1}^{t_{i}} c_{i r} ; & C_{i j}=\sum_{\substack{r=1 \\
r \neq j}}^{t_{i}} c_{i r} \\
A_{i j}(x)=\left(f_{i}(x)+1\right)\left(f_{i}(x)+2\right) \cdots\left(f_{i}(x)+k_{i j}\right) \\
B_{i j}(x)=\left(f_{i j}(x)+1\right)\left(f_{i j}(x)+2\right) \cdots\left(f_{i j}(x)+k_{i j}\right) \\
C_{i j}(x)=\left(F_{i j}(x)\right)\left(F_{i j}(x)-1\right) \cdots\left(F_{i j}(x)-k_{i j}+1\right) \\
G_{i j}(x)=\left(A_{i j}(x), B_{i j}(x)\right) ; \\
H_{i j}(x)=\left(B_{i j}(x), C_{i j}(x)\right) \\
L_{i j}(x)=\left(G_{i j}(x), H_{i j}(x)\right)
\end{array}
$$

and

$$
Q_{i j}(x)=\left(f_{i}(x)\right) ! /\left(\left(f_{i j}(x)+k_{i j}\right) !\left(F_{i j}(x)\right) !\right)
$$

where $Q_{i j}(x)$ is defined for those values of $x$ for which $f_{i j}(x)$ are all nonnegative integers.

Improving upon the results of Mordell [2], and Wright [7], McAndrew [1], proved that (in our notation) if for a particular $i$,

$$
0<a_{i 1}<A_{i}
$$

and

$$
c_{i_{1}}=0
$$

then there exists an infinity of integers $x$ for which

$$
\left(A_{i} x\right) ! / \sum_{r=1}^{t_{i}}\left(a_{i r} x+c_{i r}\right) !
$$

is an integer. In [6], the author and N. V. Rao improved upon this result, by proving that, if, together with (1.2), the conditions

$$
r_{i}<A_{i} /\left(a_{i 1}, A_{i}\right)
$$

and

(1.6) either $\quad c_{i 1}<a_{i 1} /\left(a_{i 1}, A_{i}\right) \quad$ or $\quad C_{i}<A_{i} /\left(a_{i 1}, A_{i}\right)$

hold, then there exists an infinity of integers $x$ such that

$$
\left(A_{i} x-r_{i}\right) ! x / \prod_{r=1}^{t_{i}}\left(a_{i r} x+c_{i r}\right) !
$$

is an integer. In [5] and [4] respectively, the author considered the 
question of existence of an infinity of integers $x$ which make the expressions in (1.4) and (1.7) simultaneously integers for each $i$. Recently, N. V. Rao, taking the polynomials over the domain of integers and $t_{i}=2$ for each $i$, proved the existence of an infinity of integers $x$ such that

$$
Q_{i 1}(x) \overline{G_{i 1}(x)}
$$

is an integer for each $i$ in $1 \leqq i \leqq m$, where $\overline{G_{i 1}(x)}$ is the integer coefficient G.C.D. with least positive leading coefficient of the integer coefficient polynomials $A_{i 1}(x)$ and $B_{i 1}(x)$. In fact if, for any rational coefficient $f(x), T(f)$ denotes the l.c.m. of the denominators of the coefficients of $f(x), \overline{G_{i 1}(x)}=T\left(G_{i 1}\right) G_{i 1}(x)$.

The purpose of this paper is, among other things, to improve upon the above result of Rao, simultaneously 1 , by allowing the polynomials to have their coefficients from rationals and 2, by replacing the factor $\overline{G_{i 1}(x)}$ in (1.8) by one of its divisors namely $L_{i 1}(x)$. That $L_{i 1}(x)$ can be a proper divisor of $\overline{G_{i 1}(x)}$ is seen if we take $m=1, t_{1}=2, f_{11}(x)=$ $f_{12}(x)=x^{2}-x$ and $k_{11}=2$ in which case $\overline{G_{11}(x)}=x^{2}-x+1$ while $L_{11}(x)=1$. Incidentally, the result in [6] is slightly improved by increasing the possible values of $r_{i}$ (see Cor. 1) and it turns out that McAndrew's result ((1.4)) in [1] and our result in [5] are particular cases obtainable from a more general result (Theorem IV) by taking $x$ for an arbitrary polynomial $g(x)$ over the rationals with the property that there exists an integer $x_{0}$ such that $g\left(x_{0}\right)$ is an integer.

In order to guarantee the existence of integers $x$ for which $f_{i j}(x)$ are integers, we make the following Assumption A: There exist integers $y_{i j}$ such that $f_{i j}\left(y_{i j}\right)$ are integers and the system of congruences

$$
x \equiv y_{i j}\left(\bmod T\left(f_{i j}\right)\right) \quad 1 \leqq i \leqq m, 1 \leqq j \leqq t_{\imath}
$$

admit a common solution $y_{0}$.

We note that all such common solutions are represented by

$$
x \equiv y_{0}(T)
$$

where

$$
T=\left\{T\left(f_{11}\right), T\left(f_{12}\right), \cdots, T\left(f_{m t_{m}}\right)\right\}
$$

and we observe that

$$
T\left(f_{i}\right) \mid T \quad \text { for each } i \text { in } 1 \leqq i \leqq m .
$$

We need some further notation. Let 


$$
\begin{aligned}
\hat{A}_{i j}(x) & =\left(f_{i}(x)+1\right)\left(f_{i}(x)+2\right) \cdots\left(f_{i}(x)+K_{i j}\right) \\
\hat{B}_{i j}(x) & =\left(F_{i j}(x)+1\right)\left(F_{i j}(x)+2\right) \cdots\left(F_{i j}(x)+K_{i j}\right) \\
\widehat{C}_{i j}(x) & =\left(f_{i j}(x)\right)\left(f_{i j}(x)-1\right) \cdots\left(f_{i j}(x)-K_{i j}+1\right) \\
\widehat{G}_{i j}(x) & =\left(\hat{A}_{i j}(x), \hat{B}_{i j}(x)\right) ; \quad \hat{H}_{i j}(x)=\left(\hat{B}_{i j}(x), \widehat{C}_{i j}(x)\right) \\
\hat{L}_{i j}(x) & =\left(\widehat{G}_{i j}(x), \hat{H}_{i j}(x)\right) ; \quad d_{i j}(x)=\left(B_{i j}(x), \hat{B}_{i j}(x)\right) \\
D_{i j}^{t u}(x) & =\left(f_{i}(x)+t, f_{i j}(x)+u, F_{i j}(x)-u+t\right) \\
\hat{D}_{i j}^{t u}(x) & =\left(f_{i}(x)+t, F_{i j}(x)+u, f_{i j}(x)-u+t\right) \\
\hat{Q}_{i j}(x) & =\left(f_{i}(x)\right) ! /\left(\left(f_{i j}(x)\right) !\left(F_{i j}(x)+K_{i j}\right) !\right) \\
W_{i j}(x) & =\left(f_{i}(x)\right) ! /\left(\left(f_{i j}(x)+k_{i j}\right) !\left(F_{i j}(x)+K_{i j}\right) !\right)
\end{aligned}
$$

and finally

$$
W_{i}(x)=\left(f_{i}(x)\right) ! / \prod_{r=1}^{t_{i}}\left(f_{i r}(x)+k_{i r}\right) !
$$

Now, we are in a position to state our results

THEOREM I. Under the Assumption A, there exists an infinity of integers $x$ such that

(i) $Q_{i j}(x) L_{i j}(x)$,

(ii) $\hat{Q}_{i j}(x) \hat{L}_{i j}(x)$,

(iii) $W_{i j}(x) d_{i j}(x) L_{i j}(x) \hat{L}_{i j}(x)$,

and

(iv) $W_{i}(x) d_{i j}(x) L_{i j}(x) \hat{L}_{i j}(x)$

are all simultaneously integers for each $i$ in $1 \leqq i \leqq m$ and each $j$ in $1 \leqq j \leqq t_{i}$.

THeOREM II. Under the Assumption A, if for each $i$ in $1 \leqq i \leqq m$, there is a $j(i)$ in $1 \leqq j(i) \leqq t_{i}$ such that for any integers $t, u, e, b$ satisfying

$$
1 \leqq t, u \leqq k_{i j(i)}, \quad 0 \leqq u-t \leqq k_{i j(i)}-1
$$

and

$$
\begin{aligned}
& 1 \leqq e, \quad b \leqq K_{i j(i)}, \quad 0 \leqq b-e \leqq K_{i j(i)}-1, \\
& D_{i j(i)}^{t u}(x)=1=\hat{D}_{i j(i)}^{e b}(x),
\end{aligned}
$$

then there exists an infinity of integers $x$ such that

(i) $Q_{i j(i)}(x)$,

(ii) $\hat{Q}_{i j(i)}(x)$,

and

(iii) $W_{i j(i)}(x) d_{i j(i)}(x)$,

(iv) $W_{i}(x) d_{i j(i)}(x)$

are all simultaneously integers for each $i$ in $1 \leqq i \leqq m$. 
In particular, we have:

THEOREM III. (a) If, for $1 \leqq i \leqq m, g_{i}(x)$ is a polynomial over the rationals with positive leading coefficient and if the Asssumption $A$ is satisfied for all the polynomials $r_{i j} g_{i}(x)$, then there exist an infinity of integers $x$ such that

(i) $\quad\left(R_{i} g_{i}(x)\right) ! /\left(\left(r_{i j} g_{i}(x)+k_{i j}\right) !\left(R_{i j} g_{i}(x)\right) !\right)$,

(ii) $\left(R_{i} g_{i}(x)\right) ! /\left(\left(r_{i j} g_{i}(x)\right) !\left(R_{i j} g_{i}(x)+K_{i j}\right) !\right)$,

(iii) $\quad\left(R_{i} g_{i}(x)\right) ! D_{i j}(x) /\left(\left(r_{i j} g_{i}(x)+k_{i j}\right) !\left(R_{i j} g_{i}(x)+K_{i j}\right) !\right)$,

and

(iv) $\left(R_{i} g_{i}(x)\right) ! D_{i j}(x) / \prod_{j=1}^{t_{i}}\left(r_{i j} g_{i}(x)+k_{i j}\right) !$

are all simultaneously integers for each $i$ in $1 \leqq i \leqq m$ and each $j$ in $1 \leqq j \leqq t_{i}$, where

$D_{i j}(x)=\left(\left(r_{i j} g_{i}(x)+1\right) \cdots\left(r_{i j} g_{i}(x)+k_{i j}\right),\left(R_{i j} g_{i}(x)+1\right) \cdots\left(R_{i j} g_{i}(x)+K_{i j}\right)\right)$.

(b) If in (a) the integers $k_{i j}$ and the rational numbers $r_{i j}$ are such that for each $i$ in $1 \leqq i \leqq m$, there is a $j(i)$ in $1 \leqq j(1) \leqq t_{i}$ such that

$$
r_{i j(i)} k-R_{i j(i)} n \neq 0
$$

for

$$
1 \leqq k \leqq K_{i j(i)}, \quad 1 \leqq n \leqq k_{i j(i)},
$$

then there exists an infinity of integers $x$ such that

$$
\left(R_{i} g_{i}(x)\right) ! / \prod_{j=1}^{t_{i}}\left(r_{i j} g_{i}(x)+k_{i j}\right) !
$$

is an integer for each $i$ in $1 \leqq i \leqq m$.

As an immediate consequence of Theorem III we have:

THEOREM IV. If $a_{i j}$ and $c_{i j}$ satisfy respectively (1.2) and (1.3) and if $g(x)$ is a polynomial of positive degree over the rationals with the property that there is an integer $x_{0}$ such that $g\left(x_{0}\right)$ is an integer, then there exists an infinity of positive integers $x$ such that

$$
\left(A_{i} g(x)\right) ! / \prod_{j=1}^{t_{i}}\left(a_{i j} g(x)+c_{i j}\right) !
$$

is an integer for each $i$ in $1 \leqq i \leqq m$.

Also from Theorem I, we have the following: 
COROLlaRY $1^{1}$. If $a_{i j}, c_{i j}$ and $r_{i}$ are such that for each in $1 \leqq i \leqq m$, there is a $j$ in $1 \leqq j \leqq t_{i}$ satisfying

$$
\begin{aligned}
& \text { (i) } 0<a_{i j}<A_{i}, \\
& \text { (ii) } r_{i} \leqq A_{i} /\left(a_{i j}, A_{i}\right) \\
& \text { (iii) either } c_{i j}<a_{i j} /\left(a_{i j}, A_{i}\right) \text { or } \\
& \\
& \quad C_{i j}<A_{i j} /\left(A_{i j}, A_{i}\right)
\end{aligned}
$$

then there exists an infinity of positive integers $x$ such that (1.7) is an integer for each $i$ in $1 \leqq i \leqq m$.

As remarked earlier, we observe that (1.4) is obtained from (2.6) by taking $g(x)=x$ and Cor. I is an improvement of our result in [6], since, taking $m=1, j=1$, we are increasing the range of values of $r_{1}$ (compare (1.5) and (ii) of (2.7)) and the condition (iii) of (2.7) is a consequence of (1.6) but not conversely; for example, our theorem in [6] does not help us to conclude that

$$
(8 x) ! /((2 x+3) !(4 x+1) !(2 x+1) !)
$$

is an integer infinitely often whereas our corollary does. We omit the easy verification of this statement.

LEMMA I. For each $i$ in $1 \leqq i \leqq m$ and each $j$ in $1 \leqq j \leqq t_{i}$, there exists integer coefficient polynomials $p_{i j}(x), q_{i j}(x), r_{i j}(x), s_{i j}(x)$, $t_{i j}(x), u_{i j}(x), v_{i j}(x), \hat{p}_{i j}(x), \cdots, \hat{v}_{i j}(x)$ and positive integers $\lambda_{i j}, \mu_{i j}, \nu_{i j}$, $\hat{\lambda}_{i j}, \widehat{u}_{i j}, \hat{\nu}_{i j}$, and $\zeta_{i j}$ such that

$\begin{array}{ll}\text { ( i ) } & A_{i j}(x) p_{i j}(x)+B_{i j}(x) q_{i j}(x)=\lambda_{i j} G_{i j}(x) \\ \text { ( ii ) } & B_{i j}(x) r_{i j}(x)+C_{i j}(x) s_{i j}(x)=\mu_{i j} H_{i j}(x) \\ \text { (iii) } & G_{i j}(x) t_{i j}(x)+H_{i j}(x) u_{i j}(x)=\nu_{i j} L_{i j}(x) \\ \text { (iv) } & \hat{A}_{i j}(x) \hat{p}_{i j}(x)+\hat{B}_{i j}(x) \hat{q}_{i j}(x)=\hat{\lambda}_{i j} \widehat{G}_{i j}(x) \\ \text { (v) } & \hat{B}_{i j}(x) \hat{r}_{i j}(x)+\hat{C}_{i j}(x) \hat{s}_{i j}(x)=\hat{\mu}_{i j} \hat{H}_{i j}(x) \\ \text { (vi) } & \hat{G}_{i j}(x) \hat{t}_{i j}(x)+\hat{H}_{i j}(x) \hat{u}_{i j}(x)=\hat{\nu}_{i j} \hat{L}_{i j}(x) \\ \text { (vii) } & B_{i j}(x) v_{i j}(x)+\hat{B}_{i j}(x) \hat{v}_{i j}(x)=\zeta_{i j} d_{i j}(x)\end{array}$

Proof. (i) There exist rational coefficient polynomials $\alpha_{i j}(x)$ and $\beta_{i j}(x)$ such that

$$
A_{i j}(x) \alpha_{i j}(x)+B_{i j}(x) \beta_{i j}(x)=G_{i j}(x) .
$$

Multiplying both sides of (3.1) by $\lambda_{i j}=\left\{T\left(\alpha_{i j}\right), T\left(\beta_{i j}\right)\right\}$ and writing $p_{i j}(x)=\lambda_{i j} \alpha_{i j}(x)$ and $q_{i j}(x)=\lambda_{i j} \beta_{i j}(x)$ we get (i). The proof of the other parts is similar.

LEMMA 2. For each $i$ in $1 \leqq i \leqq m$ and each $j$ in $1 \leqq j \leqq t_{i}$

1 This corollary could also be obtained from the result of [3] but no mention of this was made in [3]. 
(i ) $\lambda_{i j} \mu_{i j} \nu_{i j} Q_{i j}(x) L_{i j}(x)$

$=\mu_{i j} t_{i j}(x)\left\{A_{i j}(x) Q_{i j}(x) p_{i j}(x)+B_{i j}(x) Q_{i j}(x) q_{i j}(x)\right\}$

$+\lambda_{i j} u_{i j}(x)\left\{B_{i j}(x) Q_{i j}(x) r_{i j}(x)+C_{i j}(x) Q_{i j}(x) s_{i j}(x)\right\}$

(ii) $\hat{\lambda}_{i j} \hat{\mu}_{i j} \hat{\nu}_{i j} \hat{Q}_{i j}(x) \hat{L}_{i j}(x)$

$=\hat{\mu}_{i j} \hat{t}_{i j}(x)\left\{\hat{A}_{i j}(x) \hat{Q}_{i j}(x) \hat{p}_{i j}(x)+\hat{B}_{i j}(x) \hat{Q}_{i j}(x) \hat{q}_{i j}(x)\right\}$

$+\hat{\lambda}_{i j} \hat{u}_{i j}(x)\left\{\hat{B}_{i j}(x) \hat{Q}_{i j}(x) \hat{r}_{i j}(x)+\hat{C}_{i j}(x) \hat{Q}_{i j}(x) \hat{s}_{i j}(x)\right\}$

(iii) $\zeta_{i j} d_{i j}(x) L_{i j}(x) \hat{L}_{i j}(x) W_{i j}(x)$

$$
=L_{i j}(x) \hat{L}_{i j}(x)\left\{v_{i j}(x) \hat{Q}_{i j}(x)+\hat{v}_{i j}(x) Q_{i j}(x)\right\} \text {. }
$$

Proof. (i) follows directly from (i) (ii) (iii) of Lemma I; similarly for (ii) and (iii).

LEMMA 3. If $f^{r}(x)$ denotes the rth derivative of the rational coefficient polynomial $f(x)$, then for $r \geqq 0\left\{T(f) f^{r}(x)\right\} / r$ ! is a polynomial with integer coefficients.

Proof. Each coefficient of $f^{r}(x)$ is a product of a coefficient of $f(x)$ and a product of $r$ consecutive integers.

LEMMA 4. For each sufficiently large integer $x$ for which each $f_{i j}(x)$ is a positive integer,

$$
\begin{aligned}
& A_{i j}(x) Q_{i j}(x), B_{i j}(x) Q_{i j}(x), C_{i j}(x) Q_{i j}(x) \\
& \widehat{A}_{i j}(x) \hat{Q}_{i j}(x), \hat{B}_{i j}(x) \hat{Q}_{i j}(x), \hat{C}_{i j}(x) \hat{Q}_{i j}(x)
\end{aligned}
$$

are all positive integers.

Proof. Each of them can be expressed as a binomial coefficient.

Before proceeding to the next lemma, we introduce, for convenience, the following notation: for any positive integers $a, b$, and $c, h(a, b)$ stands for the exponent of the highest power of $b$ that divides $a$ and $D(a / b, c)$ stands for $h(a, c)-h(b, c)$.

LEMMA 5. For any positive integer a, and any prime $p$, $h(a !, p)=(a-S) /(p-1)$, where $S$ is the sum of the digits of $a$ in the representation of $a$ in the scale of $p$.

This is well known and we omit the proof.

LEMma 6. Under the assumption A, given any pair of positive integers $M$ and $N$, there exists an infinity of positive integers $x$ such that for each $i$ in $1 \leqq i \leqq m$ and each $j$ in $1 \leqq j \leqq t_{i}$ and each prime $p$ dividing $M$,

$$
D\left(W_{i j}(x), p\right)>N
$$


Proof. We prove that from among the integers satisfying (1.9), for which by the Assumption $\mathrm{A}$ all $f_{i j}(x)$ are integers, we can select an infinite number of them for which (3.2) is satisfied. $z_{0}$ being any arbitrary integer, choose $x_{0}$ such that

$$
\text { (i) } x_{0}>z_{0}, \quad \text { (ii) } x_{0} \equiv y_{0}(T) \text { and (iii) } f_{i j}\left(x_{0}\right)
$$

and $f_{i j}^{\prime}\left(x_{0}\right)$ are all positive. Let $P$ be the product of all the distinct prime factors of $M$ and $\pi$ the smallest of them. Let

$$
A=N+1+\operatorname{Max}_{\substack{1 \leq i \leq m \\ 1 \leq j \leq t_{i} \\ p \backslash P}}\left|D\left(W_{i j}\left(x_{0}\right), p\right)\right|
$$

Choose $\beta_{0}$ to be the least positive integer such that

$$
\pi^{\beta_{0}}>\operatorname{Max}_{1 \leqq i \leqq m}\left(f_{i}\left(x_{0}\right)+K_{i}\right) .
$$

Observing that any positive integer $n$ in $1 \leqq n \leqq m A$ can be uniquely expressed in the form

$$
n=(i-1) A+k, \quad 1 \leqq i \leqq m, \quad 1 \leqq k \leqq A,
$$

we define, starting with the integers $x_{0}$ and $\beta_{0}$, recurrently the integers $\gamma_{n}, \delta_{n}, x_{n}$ and $\beta_{n}$ for $1 \leqq n \leqq m A$ as follows: $\gamma_{n}$ is the least positive integer such that

$$
\pi^{\gamma_{n}}>\operatorname{Max}_{p \mid P} \frac{T f_{i}^{\prime}\left(x_{n^{\prime}-1}\right)}{p^{h\left(T_{i}^{\prime}\left(x_{n-1}\right), p\right)}}
$$

$\delta_{n}$ is the least positive integer so chosen that

(3.7) (i) $\delta_{n}>\beta_{n-1}$,

(ii) $\delta_{n}>\operatorname{Max}_{p_{\mid P}} \frac{2 h\left(T f_{i}^{\prime}\left(x_{n-1}\right), p\right)+\gamma_{n}}{1+h\left(T f_{i}^{\prime}\left(x_{n-1}\right), p\right)}$, and

(iii) $\varphi\left(P^{\gamma_{n}}\right) \mid \delta_{n}$,

$\varphi$ being Euler's totient function;

$$
x_{n}=x_{n-1}+T P^{\delta_{n}}\left(T f_{i}^{\prime}\left(x_{n-1}\right)\right)^{\delta_{n}-1} .
$$

And finally $\beta_{n}$ is the least positive integer such that

$$
\pi^{\beta_{n}}>\operatorname{Max}_{1 \leqq i \leqq m} f_{i}\left(x_{n}\right)-f_{i}\left(x_{n-1}\right) .
$$

We observe that, by virtue of (3.8), (ii) of (3.3), $x_{n}$ satisfies (1.9) and so all the $f_{i j}\left(x_{n}\right)$ are positive integers and the proof of lemma will be complete, if it is proved that $Z_{1}=x_{m A}$ satisfies (3.2). From now on the proof consists of reformulating the lemmas 2, 3, and 4 of [3] (in our notation) and adjusting their proofs.

For consideration of space, we omit the details. 
4. Proof of Theorem $I$. In the first place let us observe that, if $f(x)$ is a polynomial over the rationals, then for any integer $x$, the denominator of $f(x)$ can contain only primes $p$ in $T(f)$ to a power at most $h(T(f), p)$. Now, taking

$$
M=\prod_{i=1}^{m} \prod_{j=1}^{t_{i}} T\left(L_{i j}\right) T\left(\hat{L}_{i j}\right) T\left(d_{i j}\right) \lambda_{i j} \ell_{i j} \nu_{i j} \hat{\lambda}_{i j} \hat{\mu}_{i j} \hat{\nu}_{i j} \zeta_{i j}
$$

and

$$
N=\sum_{p \mid M \mu} h(M, p)
$$

in Lemma 6, we are guaranteed of the existence of an infinity of integers $x\left(\equiv y_{0}(\bmod T)\right)$ for which $(3.2)$ is satisfied.

For all these integers, by Lemma $4, A_{i j}(x) Q_{i j}(x), B_{i j}(x) Q_{i j}(x)$, $C_{i j}(x) Q_{i j}(x)$ are all positive integers and so by the first part of Lemma 2, $\lambda_{i j} \mu_{i j} \nu_{i j} Q_{i j}(x) L_{i j}(x)$ is an integer for each $i$ and each $j$. Since each prime factor of $\lambda_{i j} \mu_{i j} \nu_{i j}$ is necessarily a prime factor of $M$ and since for any prime $p, D\left(Q_{i j}(x), p\right) \geqq D\left(W_{i j}(x), p\right)$, the remark at the beginning of the proof and the choice of $N$ in (4.1) show that for all these integers $Q_{i j}(x) L_{i j}(x)$ is an integer.

A similar argument, taking into consideration the second and third parts of Lemma 2, shows that for all these integers,

$$
\hat{Q}_{i j}(x) \hat{L}_{i j}(x) \quad \text { and } \quad W_{i j}(x) d_{i j}(x) L_{i j}(x) \hat{L}_{i j}(x)
$$

are also integers. Further, since

$$
\begin{aligned}
& W_{i}(x) d_{i j}(x) L_{i j}(x) \hat{L}_{i j}(x) \\
& =W_{i j}(x) d_{i j}(x) L_{i j}(x) \hat{L}_{i j}(x)\left\{\frac{\left(F_{i j}(x)+K_{i j}\right) !}{\prod_{\substack{r=1 \\
r \neq j}}^{t_{i}}\left(f_{i r}(x)+k_{i r}\right) !}\right\}
\end{aligned}
$$

and since for all the integers under consideration, the expression in brackets on the R.H.S. of (4.2) is an integer the L.H.S. of the same is so. Hence Theorem I.

Proof of Theorem II. Theorem II follows from Theorem I and the following lemma:

LEMMA 7. (a) For each $i$ in $1 \leqq i \leqq m$ and each $j$ in $1 \leqq j \leqq t_{i}$, $L_{i j}(x)=1$ if and only if for any $t, u$ satisfying

$$
\begin{aligned}
& 1 \leqq t, u \leqq k_{i_{j}}, \quad 0 \leqq u-t \leqq k_{i j}-1 \\
& D_{i j}^{t u}(x)=1 .
\end{aligned}
$$

(b) For each $i$ in $1 \leqq i \leqq m$ and each $j$ in $1 \leqq j \leqq t_{i}, \hat{L}_{i j}(x)=1$ if and only if for any $e, b$ satisfying 


$$
1 \leqq e, b \leqq K_{i j} ; \quad 0 \leqq b-e \leqq K_{i j}-1, \quad \hat{D}_{i j}^{e b}(x)=1
$$

Proof. That $L_{i j}(x)$ cannot be one if for same $t, u$ satisfying (4.3) $D_{r j}^{t u}(x)$ contains as irreducible factor of positive degree, follows from the fact that $D_{i j}^{t u}(x)$ divides $L_{i j}(x)$.

If $L_{i j}(x)$ contains an irreducible factor of positive degree, say $\alpha(x)$, then for some integers $t, u$, and $v$ satisfying $1 \leqq t, u \leqq k_{i j}, 0 \leqq v \leqq$ $k_{i j}-1, \alpha(x)$ divides $f_{i}(x)+t, f_{i j}(x)+u$, and $F_{i j}(x)-v$; hence divides $t-u+v$. However, since $\alpha(x)$ is of positive degree, $t-u+v=0$ and so it divides $D_{i j}^{t u}(x)$.

The proof of (b) is similar.

Proof of Theorem III. (a) It is easily seen that $L_{i j}(x)$ and $\hat{L}_{i j}(x)$ (as related to the notation of this theorem) are 1 for each $i$ and $j$ and hence (a).

(b) The condition (2.4) ensures $D_{i j(i)}(x)=1$ and so (b) follows from (iv) of (a).

Proof of Theorem $I V$. If, for a particular $i$ in $1 \leqq i \leqq m, C_{i 1}=0$, then (2.6) is an integer for all sufficiently large $x$ for which $g(x)$ is a nonnegative integer. So, there is no loss of generality in assuming $C_{i 1}>0$ for each $i$ in $1 \leqq i \leqq m$.

If, in Theorem III (a), we take 2 for $t_{i}$ for each $i, a_{i 1}$ for $r_{i 1}$, $A_{i 1}$ for $r_{i 2}, C_{i 1}$ for $k_{i 2}$, any positive integer for $k_{i 1}$, and $g(x)$ for $g_{i}(x)$, the hypothesis of that theorem is satisfied and so by (ii) of that theorem, there exists an infinity of integers $x$ for which

$$
\left(A_{i} g(x)\right) ! /\left(\left(\alpha_{i \perp} g(x)\right) !\left(A_{i 1} g(x)+C_{i 1}\right) !\right)
$$

is an integer. From this, the theorem follows in the same way as (iv) of Theorem I followed from (iii) of it.

Proof of Corollary $I$. For each $i$ in $1 \leqq i \leqq m$, fix a $j$ for which (2.7) is satisfied.

CASE (1). Suppose both $r_{i}$ and $C_{i j}$ are not zero for each $i$ in $1 \leqq i \leqq m$.

In Theorem I, let us take for each $i, t_{i}=2, f_{i 1}(x)=a_{i j} x-r_{i}$, $f_{i 2}(x)=A_{i j} x, k_{i 1}=r_{i}+c_{i j}$, and $k_{i 2}=C_{i j}$, so that

$$
F_{i 1}(x)=f_{i 2}(x)=A_{i j}(x) \quad \text { and } \quad K_{\imath 1}=k_{i 2}=C_{i j} .
$$

It is easily seen ( $a$ proof similar to that of Lemma $I$ [6] works) that (ii) of (2.7) implies $L_{i 1}(x)=x$ and (iii) of (2.7) implies $d_{i 1}(x)=1$; further clearly $\hat{L}_{i 1}(x)=1$ and so Corollary $I$ follows from (iv) of Theorem $I$ in this case. 
Case (2). Suppose one or both of $r_{i}$ and $C_{i 1}$ are zero. In this case, the result follows trivially from case (1).

We close with a consideration of sequences of positive integers possibly more general than the sequences of positive integers represented by integer coefficient polynomials for integer values of the variable.

$\S 5$. Let $f_{n}^{i j}: 1 \leqq i \leqq m, 1 \leqq j \leqq t_{i}, n \geqq 1$ be a sequence of positive integer satisfying

(5.1) (i) for each $i$ and each $j$

$$
f_{n}^{i j} \rightarrow \infty \quad \text { as } n \rightarrow \infty
$$

(ii) there exist sequences of positive integers

$$
\begin{aligned}
& \sigma_{n}^{i j}: 1 \leqq i \leqq m, 1 \leqq j \leqq t_{i}, n \geqq 1 \\
& \zeta_{n k}^{i j}: \quad 1 \leqq i \leqq m, 1 \leqq j \leqq t_{i}, n \geqq 1, k \geqq 1
\end{aligned}
$$

such that $n_{1}>n_{2}$ implies

$$
f_{n_{1}}^{i j}-f_{n_{2}}^{i j}=\left(n_{1}-n_{2}\right) \sigma_{n_{2}}^{i j}+\left(n_{1}-n_{2}\right)^{2} \zeta_{n_{1} n_{2}}^{i j} .
$$

Defining analogously the various sequences of integers $A_{n}^{i j}, B_{n}^{i j}, C_{n}^{i j}$, $G_{n}^{i j}, H_{n}^{i j}, L_{n}^{i j}, \hat{A}_{n}^{i j}, \cdots, \hat{L}_{n}^{i j}$ and $d_{n}^{i j}$ and the sequences of rational numbers $W_{n}^{i}, W_{n}^{i j}, Q_{n}^{i j}$, and $\hat{Q}_{n}^{i j}$, (for example $A_{n}^{i j}=\left(f_{n}^{i}+1\right)\left(f_{n}^{i}+2\right) \cdots\left(f_{n}^{i}+k_{i j}\right)$ where $f_{n}^{i}=\sum_{j=1}^{t_{i}} f_{n}^{i j}$, etc), we can prove the following theorem (Theorem $\mathrm{S}$ below) and deduce from that all the theorems of $\S 2$ when the polynomials $f_{i j}(x)$ are taken over the domain of integers.

Theorem S. Given any positive integer $Z$, there exists an infinity of positive integers $n$, such that

(i) $Q_{n}^{i j}\left[L_{n}^{i j}, Z\right]$,

(ii) $\hat{Q}_{n}^{i j}\left[\hat{L}_{n}^{i j}, Z\right]$,

(iii) $W_{n}^{i j}\left[d_{n}^{i j}, Z\right]\left[L_{n}^{i j}, Z\right]\left[\hat{L}_{n}^{i j}, Z\right]$, and

(iv) $W_{n}^{i}\left[d_{n}^{i j}, Z\right]\left[L_{n}^{i j}, Z\right]\left[\hat{L}_{n}^{i j}, Z\right]$

are all positive integers simultaneously for each $i$ and each $j$ where the symbol $[a, b]$ denotes the largest divisor prime to $b$ of $a$.

A natural question in this context is whether, given a sequence $f_{n}^{i j}$ satisfying (5.1), there exists an integer coefficient polynomial say $f_{i j}(x)$ such that

$$
f_{n}^{i j}=f_{i j}(n)
$$

The author is greatly indebted to his thesis advisor Professor D. H. Lehmer for his encouragement and advice. 


\section{REFERENCES}

1. M. H. McAndrew, Note on a problem of Erdös, Proc. Camb. Phil. Soc. 55 (1959), 210-212.

2. L. J. Mordell, Integer quotients of products of factorials, Jour. Lond. Math. Soc. 34 (1959), part II, 134-138.

3. N. V. Rao, Further generalisation of a result of Mordell's, Math Annalen 146 (1962), 427-432.

4. J. Chidambarawamy, A further extension of a result of Mordell's II, Jour. Indian Math. Soc., Vol. XXVII, No. I., March 1963, 1-7.

5. — On a paper of M. H. McAndrew, Math. Annalen, 144 (1961), 56-58.

6. J. Chidambaraswamy and N. Ventateswara Rao, A further extension of a result of Mordell's, Math. Annallen 142 (1961) 246-253.

7. E. M. Wright, A generalisation of a result of Mordell, Jour. Lond. Math. Soc. 33 (1958), part IV, 476-478.

University of California, Berkeley

The University OF KANSAS 


\section{PACIFIC JOURNAL OF MATHEMATICS}

\section{EDITORS}

\author{
H. SAMELSON \\ Stanford University \\ Stanford, California \\ R. M. BLUMENTHAL \\ University of Washington \\ Seattle, Washington 98105
}

\author{
*J. DUGUNDJI \\ University of Southern California \\ Los Angeles, California 90007
}

RICHARD ARENS

University of California Los Angeles, California 90024

\section{ASSOCIATE EDITORS}
E. F. BECKENBACH
B. H. NEUMANN
F. WOLF
K. YoSIDA

\section{SUPPORTING INSTITUTIONS}

\author{
UNIVERSITY OF BRITISH COLUMBIA \\ CALIFORNIA INSTITUTE OF TECHNOLOGY \\ UNIVERSITY OF CALIFORNIA \\ MONTANA STATE UNIVERSITY \\ UNIVERSITY OF NEVADA \\ NEW MEXICO STATE UNIVERSITY \\ OREGON STATE UNIVERSITY \\ UNIVERSITY OF OREGON \\ OSAKA UNIVERSITY \\ UNIVERSITY OF SOUTHERN CALIFORNIA
}

\author{
STANFORD UNIVERSITY \\ UNIVERSITY OF TOKYO \\ UNIVERSITY OF UTAH \\ WASHINGTON STATE UNIVERSITY \\ UNIVERSITY OF WASHINGTON \\ * * * * \\ AMERICAN MATHEMATICAL SOCIETY \\ CHEVRON RESEARCH CORPORATION \\ TRW SYSTEMS \\ NAVAL ORDNANCE TEST STATION
}

Mathematical papers intended for publication in the Pacific Journal of Mathematics should be typewritten (double spaced). The first paragraph or two must be capable of being used separately as a synopsis of the entire paper. It should not contain references to the bibliography. Manuscripts may be sent to any one of the four editors. All other communications to the editors should be addressed to the managing editor, Richard Arens at the University of California, Los Angeles, California 90024.

50 reprints per author of each article are furnished free of charge; additional copies may be obtained at cost in multiples of 50 .

The Pacific Journal of Mathematics is published monthly. Effective with Volume 16 the price per volume (3 numbers) is $\$ 8.00$; single issues, $\$ 3.00$. Special price for current issues to individual faculty members of supporting institutions and to individual members of the American Mathematical Society: $\$ 4.00$ per volume; single issues $\$ 1.50$. Back numbers are available.

Subscriptions, orders for back numbers, and changes of address should be sent to Pacific Journal of Mathematics, 103 Highland Boulevard, Berkeley 8, California.

Printed at Kokusai Bunken Insatsusha (International Academic Printing Co., Ltd.), No. 6, 2-chome, Fujimi-cho, Chiyoda-ku, Tokyo, Japan.

\section{PUBLISHED BY PACIFIC JOURNAL OF MATHEMATICS, A NON-PROFIT CORPORATION}

The Supporting Institutions listed above contribute to the cost of publication of this Journal, but they are not owners or publishers and have no responsibility for its content or policies.

* Paul A. White, Acting Editor until J. Dugundji returns. 


\section{Pacific Journal of Mathematics}

\section{Vol. 17, No. 2 \\ February, 1966}

Henry A. Antosiewicz, Boundary value problems for nonlinear ordinary

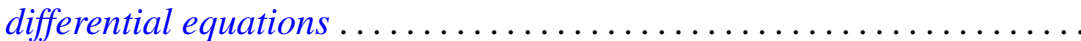

Bernard Werner Levinger and Richard Steven Varga, Minimal Gerschgorin sets. II ........................................

Paul Camion and Alan Jerome Hoffman, On the nonsingularity of complex matrices........................................ 211

J. Chidambaraswamy, Divisibility properties of certain factorials ........ 215

J. Chidambaraswamy, A problem complementary to a problem of Erdös .... 227

John Dauns, Chains of modules with completely reducible quotients ...... 235

Wallace E. Johnson, Existence of half-trajectories in prescribed regions and asymptotic orbital stability ............................ 243

Victor Klee, Paths on polyhedra. II . ........................ 249

Edwin Haena Mookini, Sufficient conditions for an optimal control problem in the calculus of variations ............................ 263

Zane Clinton Motteler, Existence theorems for certain quasi-linear elliptic equations........................................... 279

David Lewis Outcalt, Simple n-associative rings ............... 301

David Joseph Rodabaugh, Some new results on simple algebras ......... 311

Oscar S. Rothaus, Asymptotic properties of groups generation ........... 319

Ernest Edward Shult, Nilpotence of the commutator subgroup in groups admitting fixed point free operator groups .............

William Hall Sills, On absolutely continuous functions and the

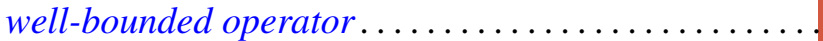

Joseph Gail Stampfli, Which weighted shifts are subnormal ..

Donald Reginald Traylor, Metrizability and completeness in normal Moore spaces 